\title{
New Clothing Resistance Scheme for Estimating Outdoor Environmental Thermal Load
}

\author{
Ferenc Ács ${ }^{\mathrm{A}^{*}}$, Erzsébet Kristóf ${ }^{\mathrm{B}}$, Annamária Zsákaic \\ Received: October 23, 2019 | Revised: December 25, 2019| Accepted: December 26, 2019 \\ DOI: $10.5937 / g p 23-23717$
}

\begin{abstract}
A new clothing resistance model for estimating outdoor thermal load is proposed and its behavior is analyzed in different weather conditions. It is based on clothed human body energy balance considerations; the human treated is a walking human in outdoor conditions. Weather and human data are taken from the internet site of the Hungarian Meteorological Service and from a Hungarian human dataset, respectively. Environmental thermal load is characterized in terms of clothing resistance $r_{c l}$ and operative temperature. The model's main strength is that it simulates metabolic rate $M$ as simply as possible. $r_{c l}$ deviations caused by personal variations of $M$ are the largest in extreme cold and warm conditions, in the comfort zone this effect is non-essential. $r_{\mathrm{cl}}$ deviations caused by wind speed variations can be especially large in large heat excess cases. Further model tests are needed for more extreme conditions.
\end{abstract}

Keywords: weather; Hungarian human; environmental thermal load; clothing resistance; operative temperature; metabolic activity; wind speed

\section{Introduction}

The past of modeling of clothing resistance, assuming steady-state conditions and serving as an outdoor environmental thermal indicator, goes back to the nineteen thirties (Herrington et al., 1937). Herrington et al.'s approach is modified by Burton and Edholm (1955) to achieve more suitable applications in different climate regions of the Earth (e.g. Auliciems \& de Freitas, 1976; Auliciems \& Kalma, 1979; de Freitas, 1979; Yan \& Oliver, 1996; Yan, 2005; Robaa \& Hasanean, 2007) and in different weather types (Błażejczyk \& Krawczyk, 1994). In all these studies, clothing is characterized by its thermal insulation rate, that is, it is not viewed as thermal regulator medium, which can equally have cooling/ heating effects on the human body in heat/cold stresses to reach clothed human body - outdoor environment thermal equilibrium. Only positive values of clothing resistance $r_{c l}$ are considered when viewing clothing as a thermal insulation medium, with negative values, referring to warm/hot climates or weather, not being considered and equating these values simply to zero (e.g. Yan, 2005). A human is represented via metabolic cost $\mathrm{M}$, which is a constant referring to either a standing human or a human walking at a speed of 4-5 km per hour (e.g. Błażejczyk \& Krawczyk, 1994; Auliciems \& de Freitas, 1976; de Freitas, 1979). Interperson variation effects on $\mathrm{r}_{\mathrm{cl}}$ are not treated at all.

The aim of this study is to present a new clothing resistance model and to analyze its behavior in differ-

A Eötvös Loránd University, Faculty of Science, Department of Meteorology, Pázmány Péter sétány 1/A., Budapest, Hungary, acs@caesar.elte.hu

B Eötvös Loránd University, Faculty of Science, Department of Meteorology, Pázmány Péter sétány 1/A., Budapest, Hungary and Eötvös Loránd University, Faculty of Science, Excellence Center, Brunszvik utca 2, Martonvásár, Hungary, ekristof86@caesar.elte.hu

c Eötvös Loránd University, Faculty of Science, Department of Human Anthropology, Pázmány Péter sétány 1/C., Budapest, Hungary, zsakaia@caesar.elte.hu

* Corresponding author: Ferenc Ács; e-mail: acs@caesar.elte.hu; telephone: +36302929408 
ent weather conditions. The model is able to treat interperson variation effect in estimating metabolic cost $\mathrm{M}$ as simply as possible, this is the main strength of the scheme recommended. The scheme's behavior is analyzed strictly according to thermal equilibrium principles between the clothed human body and the outdoor environment. This means that $\mathrm{r}_{\mathrm{cl}}$ is interpreted as the heating/cooling effect of clothing on the human body in cold/warm weather; correspondingly it can possess not only positive values in cold weather, but also negative values in warm weather in order to maintain ther- mal equilibrium. By analyzing the scheme's behavior our goal is also to compare the effect of interperson variations and the effect of changing wind velocity on the evolution of $\mathrm{r}_{\mathrm{cl}}$ in different weather conditions.

The scheme is briefly presented in section 2. Basic information regarding both the environmental and human data is described in section 3 . The scheme's behavior in terms of $\mathrm{r}_{\mathrm{cl}}$ is considered in section 4.1, and the comparative analysis of wind and interperson variation effects on $r_{c l}$ is presented in section 4.4. Concluding remarks are given in section 5 .

\section{Clothing resistance model}

The model supposes that 1) the clothing covers the human body completely, 2) the clothing sticks strongly to the skin surface, 3) the clothing's albedo is equal to the skin's albedo, 4) the human is walking at a speed of $1.1 \mathrm{~ms}^{-1}$ without sweating, 5) the latent heat of evaporation from the dry skin and from the clothing is equal and 6) the human body is represented as a single segment, that is a one-node human body model (Katić et al., 2016) is used. This physical representation of the clothed human body-air environment system is similar to that presented in Campbell and Norman (1998). The formulae and interpretation of clothing resistance parameter is new.

\section{Basic equations of thermal indicators}

The model's basic equations calculate the clothing resistance parameter $r_{c l}$ and the operative temperature $T_{0}$. These can be expressed as variables interdependent of each other or as variables that depend upon environmental factors; here both representations are presented,

$$
\begin{aligned}
& T_{o}=T_{a}+\frac{R_{n i}}{\rho \cdot c_{p}} \cdot r_{H r}, \\
& T_{o}=T_{S}-\left(r_{H r}+r_{c l}\right) \cdot \frac{M-\lambda E_{s d}-\lambda E_{r}-W}{\rho \cdot c_{p}}, \\
& r_{c l}=\rho \cdot c_{p} \cdot \frac{T_{S}-T_{a}}{M-\lambda E_{s d}-\lambda E_{r}-W}-r_{H r} \cdot\left[\frac{R_{n i}}{M-\lambda E_{s d}-\lambda E_{r}-W}+1\right], \\
& r_{c l}=\rho \cdot c_{p} \cdot \frac{T_{S}-T_{o}}{M-\lambda E_{s d}-\lambda E_{r}-W}-r_{H r},
\end{aligned}
$$

where $\rho$ is air density $\left[\mathrm{kgm}^{-3}\right], c_{p}$ is specific heat at constant pressure $\left[\mathrm{Jgg}^{-10} \mathrm{C}^{-1}\right], T_{a}$ is air temperature $\left[{ }^{\circ} \mathrm{C}\right], T_{S}$ is skin temperature $\left[{ }^{\circ} \mathrm{C}\right]$ (a constant, $34^{\circ} \mathrm{C}$ ), $r_{\mathrm{Hr}}$ is the combined resistance for expressing thermal radiative and convective heat exchanges [ $\left.\mathrm{sm}^{-1}\right], R_{n i}$ is the isothermal net radiation flux density [ $\left.\mathrm{Wm}^{-2}\right], \mathrm{M}$ is the metabolic heat flux density $\left[\mathrm{Wm}^{-2}\right], \lambda E_{s d}$ is the latent heat flux density of dry skin $\left[\mathrm{Wm}^{-2}\right], \lambda E_{r}$ is the respiratory latent heat flux density $\left[\mathrm{Wm}^{-2}\right]$ and $W$ is the mechanical work flux density $\left[\mathrm{Wm}^{-2}\right]$ referring to the activity under consideration, in this case walking. Of course, eqs. (1) and (2) give the same result as eqs. (3) and (4).

\section{Parameterizations of environmental and human factors}

To use eqs. (1), (2), (3) and (4), we have to parameterize $R_{n i}, r_{H r}, M, \lambda E_{r}, \lambda E_{s d}$ and $W . R_{n i}$ and $r_{H r}$ comprise environmental, while $M, \lambda E_{8}, \lambda E_{s d}$ and $W$ human effects. Net radiation is approached by isothermal net radiation as

$$
R_{n i}=S \cdot\left(1-\alpha_{c l}\right)+\epsilon_{a} \sigma T_{a}^{4}-\epsilon_{c l} \sigma T_{a}^{4},
$$


where $S$ is the global radiation, $\alpha_{c l}$ is the albedo of clothing, $\epsilon_{a}$ is the atmospheric emissivity and $\epsilon_{c l}$ is the emissivity of clothing or skin. In this scheme $\alpha_{c l}=0.25-0.27, \in_{c l}=1$. Global radiation is estimated via relative sunshine duration $r s d$ according to Mihailović and Ács (1985),

$$
S=Q_{0} \cdot[\alpha+(1-\alpha) \cdot r s d],
$$

where $Q_{o}$ is the global radiation constant $\left[\mathrm{MJ} \cdot \mathrm{m}^{-2} \cdot\right.$ hour $\left.^{-1}\right]$ referring to clear sky conditions and a 1-hour time period and $\alpha$ is the corresponding dimensionless constant referring to the same hour. $\epsilon_{a}$ depends on clear sky emissivity $\epsilon_{c s}$ and cloudiness $N$ (o for cloudless and 1 for completely overcast conditions),

$$
\begin{aligned}
& \epsilon_{a}=\epsilon_{c s} \cdot\left(1-N^{1.6}\right)+0.9552 \cdot N^{1.6}, \\
& \epsilon_{c s}=0.51+0.066 \cdot \sqrt{e},
\end{aligned}
$$

where $e$ is the vapor pressure [Pa]. $\in_{c s}$ and $\in_{a}$ are given according to Brunt (1932) and Konzelmann et al. (1994), respectively.

The combined resistance for expressing the thermal radiative and convective heat exchanges $r_{H r}$ is given by

$$
\frac{1}{r_{H r}}=\frac{1}{r_{H a}}+\frac{1}{r_{R}} \text { with } r_{H a}\left[s^{-1}\right]=7.4 \cdot 41 \cdot \sqrt{\frac{D}{U_{1.5}}}, \frac{1}{r_{R}}=\frac{4 \epsilon_{c l} \sigma T_{a}^{3}}{\rho c_{p}},
$$

where $D[\mathrm{~m}]$ is diameter of the cylindrical body used to approach the human body (Campbell \& Norman, 1998), $U_{1.5}$ is the wind speed at $1.5 \mathrm{~m}$ (around breast height). $U_{1.5}$ is calculated from $U_{10}$ (wind speed at a height of $10 \mathrm{~m}$ ) using a logarithmic wind profile approach supposing neutral thermal stability. In this study, the effect of the direction of a walking human compared to the direction of wind speed is not considered, that is $U_{1.5}$ does not represent air speed relative to the human body.

According to Weyand et al. (2010) a walking human's $M$ can be expressed as,

$$
M=M_{b}+M_{w} \text {, }
$$

where $M_{b}$ is the basal metabolic rate $[W]$ (sleeping human) and $M_{w}$ is the metabolic rate $[W]$ referring to walking. Both terms can be estimated if gender, age [year], body mass $M_{b o}[\mathrm{~kg}]$ and body length $L_{b o}[\mathrm{~cm}]$ of the human considered are known. Frankenfield et al. (2005), reviewing different parameterizations, state that Mifflin et al.'s (1990) $M_{b}$ parameterization is one of the best,

$$
\begin{aligned}
& M_{b}^{\text {male }}\left[k c a l \cdot \text { day }^{-1}\right]=9.99 \cdot M_{b o}+6.25 \cdot L_{b o}-4.92 \cdot a g e+5, \\
& M_{b}^{\text {female }}\left[k \mathrm{kal} \cdot \mathrm{day}^{-1}\right]=9.99 \cdot M_{b o}+6.25 \cdot L_{b o}-4.92 \cdot \text { age }-161,
\end{aligned}
$$

To be able to obtain $M_{b}$ in [ $\left.\mathrm{Wm}^{-2}\right]$, the human body surface $A\left[\mathrm{~m}^{2}\right]$ also has to be estimated. The Dubois and Dubois (1915) parameterization is used for estimating $A\left[\mathrm{~m}^{2}\right]$ taking $M_{b o}$ and $L_{b o}$ as inputs,

$$
A=0.2 \cdot M_{b o}^{0.425} \cdot\left(\frac{L_{b o}}{100}\right)^{0.725}
$$

$M_{w}$ is parameterized according to Weyand et al. (2010) as follows,

$$
M_{w}=1.1 \cdot \frac{3.80 \cdot M_{b o} \cdot\left(\frac{L_{b o}}{100}\right)^{-0.95}}{A},
$$

Formula (1) in Weyand et al. (2010) refers to a walking distance of $1 \mathrm{~m}$. Since the reference walking speed in our model is $1.1 \mathrm{~ms}^{-1}$, Weyand et al.'s (2010) formula (1) is multiplied by the factor 1.1, and dividing this by $A$, we get $M_{w}$ in $\left[\mathrm{Wm}^{-2}\right]$. 
The $\lambda E_{s d}+\lambda E_{r}$ sum can be expressed as a function of $M$ according to Campbell and Norman (1998),

$$
\lambda E_{r}+\lambda E_{s d}=\frac{e_{S}\left(T_{S}\right)-e_{a}}{p_{a}} \cdot[1.83 \cdot M+237.6]
$$

where $e_{S}\left(T_{S}\right)$ is the saturation vapor pressure at skin temperature, $e_{a}$ is the actual vapor pressure, $p_{a}$ is the atmospheric pressure $\left[\mathrm{hPa}\right.$ ]. The constant 237.6 is given in $\left[\mathrm{Wm}^{-2}\right] . W$ depends upon $M$. According to Auliciems and Kalma (1979), $W$ can be expressed as

$$
W=0.25 \cdot\left(M-M_{b}\right) \text {. }
$$

\section{Data}

The scheme uses atmospheric and human data as input data. Atmospheric data refer to the town of Martonvásár (geographical latitude $47.31^{\circ} \mathrm{N}$, geographical longitude $18.79^{\circ} \mathrm{E}$ ) located in the Central Transdanubian region of Hungary (Figure 1a).
The first author of this study ran on 112 occasions in total at Martonvásár's athletics track (Figure 1b) in the period August 9, 2016 - May 23, 2018.

This is, on average, one occasion every six days. The time duration of each occasion was about 45-60 min-

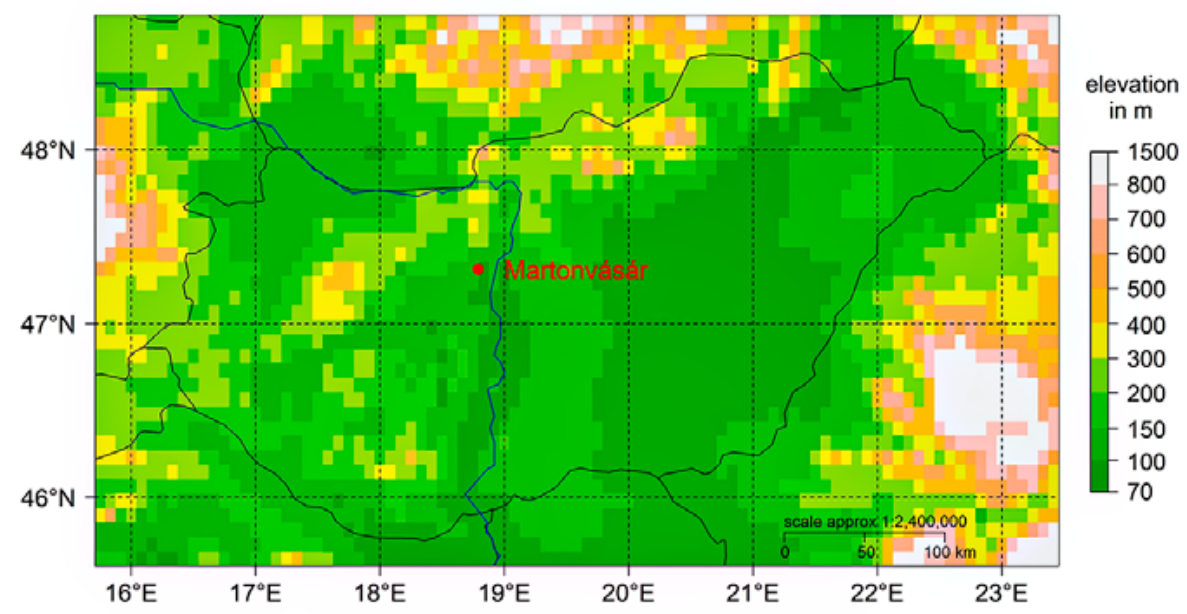

Figure 1a. Area distribution of the elevation intervals and location of Martonvásár in Hungary ${ }^{1}$

According to Feddema (Ács et al., 2015) Martonvásár's climate is "cool and dry with extreme variations of temperature". Annual potential evapotranspiration is about $700 \mathrm{~mm}$ (cool climate), annual precipitation is about $550 \mathrm{~mm}$, so there is an annual water deficit of about $150 \mathrm{~mm}$ (dry climate). Annual air temperature and annual average global radiation are $10-11^{\circ} \mathrm{C}$ and $150 \mathrm{Wm}^{-2}$, respectively. So, annual $\mathrm{R}_{\mathrm{ni}}$ is about $70 \mathrm{Wm}^{-2}$. Wind speed of $1-2 \mathrm{~ms}^{-1}$ is the most frequent (about 30\%). This and the average annual air temperature result $\mathrm{r}_{\mathrm{Hr}}$ of about $100 \mathrm{sm}^{-1}$. So, the average annual $\mathrm{T}_{\mathrm{o}}$ is $16-17^{\circ} \mathrm{C}$. Correspondingly the mean annual clothing resistance is between 0.4 and $0.8 \mathrm{Clo}$.

\footnotetext{
1 Figures from 1a to 8 are constructed by R programming language (R Core Team, 2019). Figure 1 is created by using functions from packages mapdata (Brownrigg, 2018), maps (Brownrigg et al., 2018), geomapdata (Lees, 2012), GEOmap (Lees, 2018), fields (Nychka et al., 2017).
}

utes; the beginning and the end of the time period is regularly registered. On these occasions human and meteorological data were also collected. In this study,

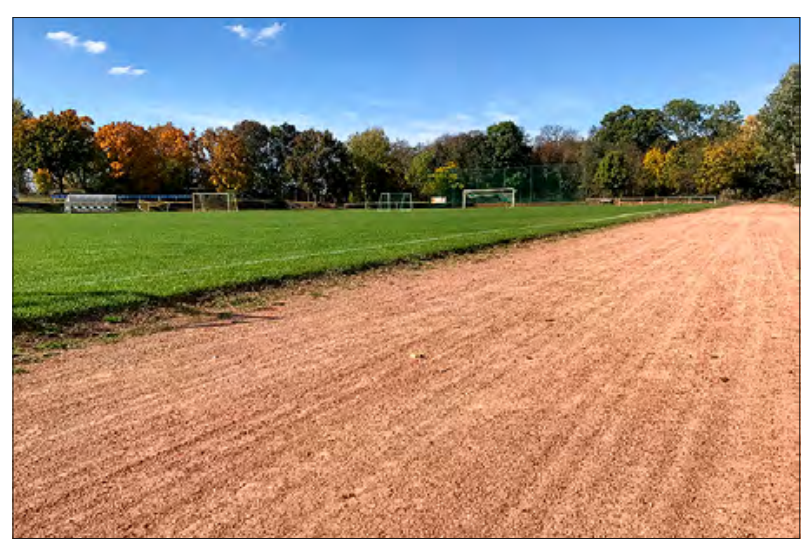

Figure 1b. The athletics track beside football field in Martonvásár (photo is made by Ferenc Ács) 
human data collected (sweating rate, running speed, etc.) are not used. From meteorological data air temperature, air humidity, average and wind gust speeds and atmospheric pressure data are taken from the website of Hungarian Meteorological Service (HMS) for that 10-minute period in the middle of running event's time period. The HMS station-football field beeline distance in Martonvásár is 100-150 m. Relative sunshine duration and cloudiness are visually observed. Anticyclonic weather types prevailed during most of the occasions, there was no case with rain of average or large intensity. The lowest/highest air temperatures are -10 and $34^{\circ} \mathrm{C}$, respectively. Isothermal net radiation fluxes ranged between -82.6 and $482.4 \mathrm{Wm}^{-2}$. Relative humid- ity values ranged between 31 and $100 \%$. Average wind speed changed from calm $\left(0.1 \mathrm{~ms}^{-1}\right)$ to high values $(8.6$ $\mathrm{ms}^{-1}$ ). Wind gust was below $1 \mathrm{~ms}^{-1}$ twice, the maximum value registered was $13.4 \mathrm{~ms}^{-1}$. Lastly, atmospheric pressure ranged from 999 to $1039 \mathrm{hPa}$.

\section{Human data}

The model needs the following human data as input data: gender, age, body mass and body length. These data are presented in Table 1 for three adult Hungarian males. Data are taken from a Hungarian human dataset constructed at the Department of Biological Anthropology, Eötvös Loránd University, Budapest (Zsákai et al., 2015).

Table 1. Human characteristics of three Hungarian adult males

\begin{tabular}{|l|c|c|c|c|c|c|}
\hline Humans & $\begin{array}{c}\text { Age } \\
{[y e a r s]}\end{array}$ & $\begin{array}{c}\text { Body } \\
\text { mass }[\mathrm{kg}]\end{array}$ & $\begin{array}{c}\text { Body length } \\
{[\mathrm{cm}]}\end{array}$ & $\begin{array}{c}\text { Basal meta- } \\
\text { bolic flux } \\
\text { density }\left[\mathrm{Wm}^{-2}\right]\end{array}$ & $\begin{array}{c}\text { Walking energy } \\
\text { flux density } \\
{\left[\mathrm{Wm}^{-2}\right]}\end{array}$ & $\begin{array}{c}\text { Total energy } \\
\text { flux density } \\
{\left[\mathrm{Wm}^{-2}\right]}\end{array}$ \\
\hline Person 1: adult Hungarian male & 64 & 89.0 & 190.1 & 36.0 & 94 & 130.0 \\
\hline Person 2: adult Hungarian male & 53 & 95.0 & 179.0 & 38.0 & 108.0 & 146.0 \\
\hline Person 3: adult Hungarian male & 24 & 120.0 & 179.0 & 42.0 & 124.0 & 166.0 \\
\hline
\end{tabular}

Note that the interperson variation of $\mathrm{M}$ is not larger than $36 \mathrm{Wm}^{-2}$.

\section{Results}

First, the scheme's general behavior is considered, then its sensitivity to wind variations and interperson variations of $\mathrm{M}$ is analyzed. Lastly, the results obtained by two sensitivity tests are compared to each other.

\section{The scheme's behavior}

The scheme's behavior is analyzed in terms of $r_{c l}$ and $\mathrm{r}_{\mathrm{cl}}-\mathrm{T}_{\mathrm{o}}$ relationships. Evolution of $\mathrm{r}_{\mathrm{cl}}$ is simulated for 112 occasions, when completely different environmental conditions prevailed. The most important atmospheric variables (air temperature, isothermal net radiation, average wind and wind gust) for the occasions considered are presented in Figures 2 and 3.

The referring $\mathrm{r}_{\mathrm{cl}}$ evolution for person 1 using average wind speed and wind gust speed values is presented in Figure 4.
Inspecting Fig. 4 it can be revealed that $r_{c l}$ values are governed by all three meteorological variables (temperature, radiation, wind) (e.g. Matzarakis, 2007), but it seems to be that the most important variables are air temperature and isothermal net radiation. This can be easily seen comparing the evolution of $\mathrm{T}_{\mathrm{a}}$ and $\mathrm{R}_{\mathrm{ni}}$ in Fig. 2 and the evolution of $r_{c l}$ in Fig. 4. If their combined forcing is positive for the given $M$ (heat excess), $r_{c l}$ is negative (cooling is needed to reach heat balance, that is thermal neutrality), and vice versa, when their combined forcing is negative (heat deficit), $\mathrm{r}_{\mathrm{cl}}$ is positive (heating is needed to reach heat balance, that is thermal neutrality). Note that so far, only positive $r_{c l}$ values are considered in the scientific literature because of the heating effect of clothing. Since humans do not use garments with a cooling effect in everyday life, so far negative $r_{c l}$ values

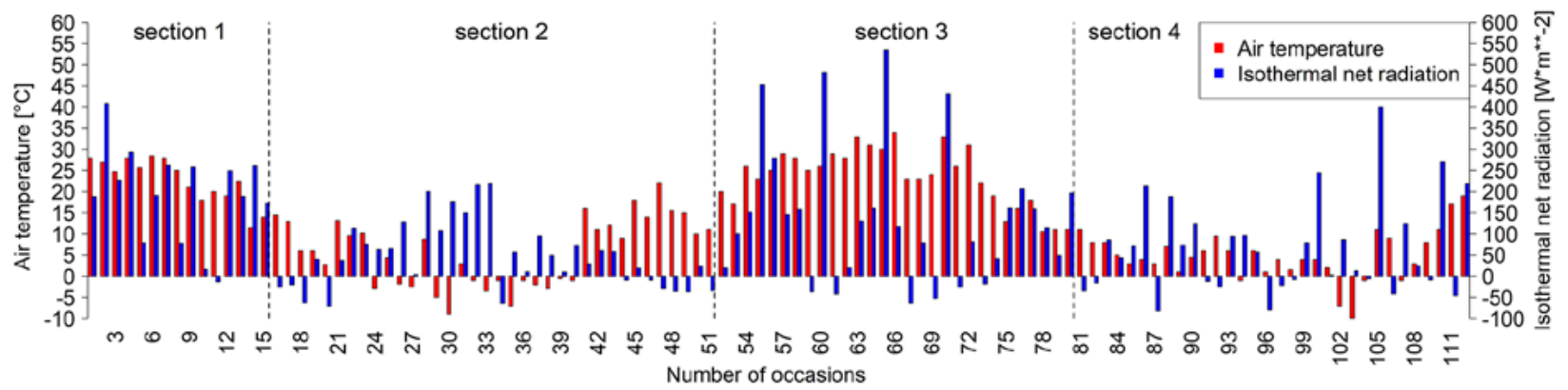

Figure 2. Evolution of representative air temperature and isothermal net radiation values for a running event at the Martonvásár athletics track 


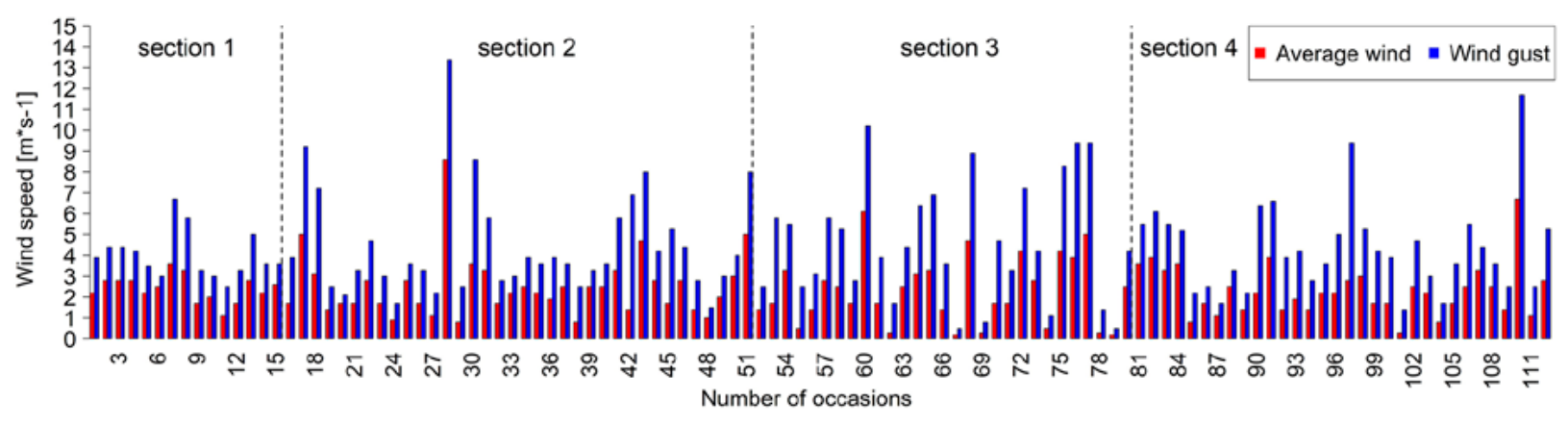

Figure 3. Evolution of average wind speed and wind gust speed on running occasions at the Martonvásár athletics track

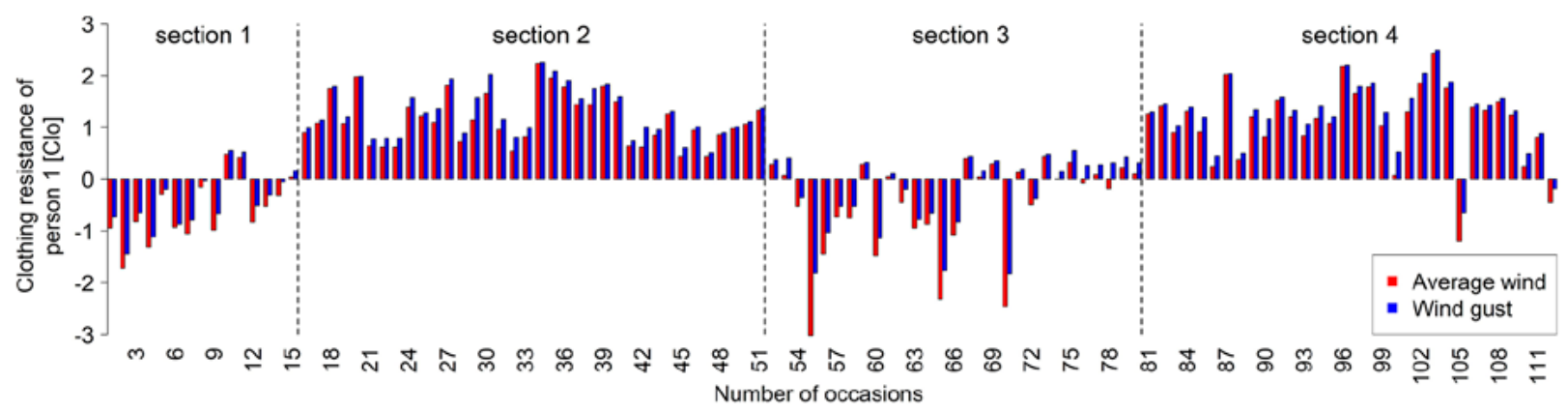

Figure 4. Evolution of clothing resistance of person 1 for average wind speed and wind gust speed values on running occasions at the Martonvásár athletics track

in the scientific literature have not been considered at all. As we see in Fig. 4, $\mathrm{r}_{\mathrm{cl}}$ changes can be divided into four sections. In the first section (occasions 1-15, except occasions 10, 11, 15) (from August 9, 2016 to October 15, 2016) $\mathrm{r}_{\mathrm{cl}}$ values are negative; in the second section (occasions 16-51) (from October 25, 2016 to April 23, 2017), $\mathrm{r}_{\mathrm{cl}}$ values are positive; in the third section (occasions 52-80) (from April 26, 2019 to November 1, 2017) $r_{c l}$ values are negative or weakly positive (close to zero) and lastly, in the fourth section (occasions 81-112) (from November 5, 2017 to May 23, 2018), $\mathrm{r}_{\mathrm{cl}}$ values are mostly positive except occasions 105 and 112.

As it was mentioned, $\mathrm{r}_{\mathrm{cl}}$ is governed by all atmospheric forcing variables (temperature, radiation, humidity, wind). It is interesting to see the behavior of $\mathrm{r}_{\mathrm{cl}}$ for occasions 16 and 17, (October 25 and 29, between 3-4 pm) when $15>\mathrm{T}_{\mathrm{a}}>13{ }^{\circ} \mathrm{C}$ but $-26<\mathrm{R}_{\mathrm{ni}}<-20 \mathrm{Wm}^{-2}$ for higher (5.0 and $9.2 \mathrm{~ms}^{-1}$ ) and lower (1.7 and $3.9 \mathrm{~ms}^{-}$ ${ }^{1}$ ) wind speed values. In both cases $\mathrm{T}_{\mathrm{a}}$ is around $14{ }^{\circ} \mathrm{C}$, which together with $\mathrm{R}_{\mathrm{ni}}$ being around $-20 \mathrm{Wm}^{-2}$ results in an $r_{c l}$ value of about 1 Clo. $r_{c l}$ referring to a larger wind speed is, of course, larger than $r_{c l}$ referring to a lower wind speed, but not much larger. Logically $r_{\mathrm{cl}}$ values are larger for wind gust than for average wind for about 0.05-0.10 Clo, the corresponding $\mathrm{T}_{\mathrm{o}}$ value changes are $0.3-0.5^{\circ} \mathrm{C}$. One typical summer case is represented on occasion 60 (June 13, between 10-11 am). In this case, $\mathrm{T}_{\mathrm{a}}=26{ }^{\circ} \mathrm{C}, \mathrm{R}_{\mathrm{ni}}=482 \mathrm{Wm}^{-2}$ and the wind is strong (average wind speed 6.1, gust wind speed $10.2 \mathrm{~ms}^{-1}$ ), the referring $\mathrm{r}_{\mathrm{cl}}$ and $\mathrm{T}_{\mathrm{o}}$ values are -1.47 and $-1.14 \mathrm{Clo}, 51.2$ and $47.0^{\circ} \mathrm{C}$, respectively. As we see, in this case the effect of wind changes on $r_{c l}$ seems to be stronger than in the former two cases.

It is also important to see the model's behavior in the comfort zone (thermal neutrality), which is defined as the zone where $-0.2<\mathrm{r}_{\mathrm{cl}}<0.2$ Clo (a zone around $\mathrm{r}_{\mathrm{cl}}=\mathrm{o}$ line). Among the 112 occasions there are 12 such occasions (occasions 8, 15, 53, 61, 68, 71, 74, $76,77,78,80$ 100) for average wind speed and person 1. Meteorological forcings together with $\mathrm{r}_{\mathrm{cl}}, \mathrm{T}_{\mathrm{o}}$ and $\mathrm{r}_{\mathrm{Hr}}$ values are presented in Table 2.

Inspecting meteorological forcings one can see that they can differ significantly, this is especially conspicuous for occasions 71 (clear sky, dry land-surface), 78 (fog, moist grass) and 100 (partly cloudy, snow-covered land-surface), when sky and land-surface conditions also differed enormously. The average value of meteorological forcings and human thermal variables are also given in Table 2 . The average and the instantaneous values of meteorological forcings and human thermal variables are in accordance. These results are consistent with literature results, that is, they are comparable to them (e.g. Potchter et al., 2018).

\section{Sensitivity of $r_{c l}$ to wind speed variations}

Wind speed variation is represented by comparison of average wind and wind gust referring to a 10-minute time interval. As mentioned, the 10-minute time interval is in the middle or approximately in the middle of the running time period. $\mathrm{r}_{\mathrm{cl}}$ deviations for person 1 to 
Table 2. Instantaneous and average values of meteorological and human thermal variables referring to thermal neutrality $\left(-0.2<\mathrm{r}_{\mathrm{cl}}<0.2 \mathrm{Clo}\right)$ on 12 occasions registered in the period August 9, 2016 - May 23, 2018.

\begin{tabular}{|c|c|c|c|c|c|c|}
\hline Occasion & Air temp. $\left[{ }^{\circ} \mathrm{C}\right]$ & $\begin{array}{c}\text { Net } \\
\text { isothermal } \\
\left.\text { rad.[Wm }{ }^{-2}\right]\end{array}$ & $\begin{array}{c}\text { Average wind } \\
\text { speed }\left[\mathrm{ms}^{-1}\right]\end{array}$ & $\begin{array}{c}\text { Clothing } \\
\text { resistance } \\
{[\mathrm{Clo}]}\end{array}$ & $\begin{array}{c}\text { Operative } \\
\text { temp. }\left[{ }^{\circ} \mathrm{C}\right]\end{array}$ & $\begin{array}{c}\text { Combined } \\
\text { heat exchange } \\
\text { resistance }\left[\mathrm{sm}^{-1}\right]\end{array}$ \\
\hline 8 & 25 & 78.3 & 3.3 & -0.15 & 30.0 & 77 \\
\hline 15 & 14 & 172.9 & 2.6 & 0.04 & 26.4 & 87 \\
\hline 53 & 17 & 100.4 & 1.7 & 0.07 & 25.1 & 97 \\
\hline 61 & 29 & -42.6 & 1.7 & 0.05 & 25.8 & 91 \\
\hline 68 & 23 & 79.7 & 4.7 & 0.04 & 27.6 & 69 \\
\hline 71 & 26 & -26.2 & 1.7 & 0.13 & 24.0 & 93 \\
\hline 74 & 19 & 42 & 0.5 & -0.01 & 23.5 & 128 \\
\hline 76 & 16 & 206.8 & 3.9 & -0.07 & 29.0 & 76 \\
\hline 77 & 18 & 159.0 & 5.0 & 0.09 & 27.1 & 69 \\
\hline 78 & 10.5 & 114 & 0.3 & -0.18 & 24.6 & 149 \\
\hline 80 & 11.0 & 197 & 2.5 & 0.10 & 25.5 & 89 \\
\hline 100 & 4.0 & 244.9 & 1.7 & 0.07 & 24.9 & 103 \\
\hline
\end{tabular}

variations of wind speed in the course of the running occasions can be seen in Figure 4. $r_{\mathrm{cl}}$ deviations vary from very small (0.02 Clo) through middle (0.2-0.3 Clo) to large (0.5-0.6 Clo) or very large (about $1 \mathrm{Clo}$ ) values. Small $r_{c l}$ changes seem to be more typical in the case of heat deficit (for $\mathrm{T}_{\mathrm{a}}>0, \mathrm{R}_{\mathrm{ni}}<0$; for $\mathrm{T}_{\mathrm{a}}<0, \mathrm{R}_{\mathrm{ni}}>\mathrm{o}$ or $\mathrm{T}_{\mathrm{a}}<0, \mathrm{R}_{\mathrm{ni}}<0$ ), this can be observed for occasions 20 , $34,39,49,69,81,96$ and 103. Note that on occasion 30 $\left(\mathrm{T}_{\mathrm{a}}=-9{ }^{\circ} \mathrm{C}, \mathrm{R}_{\mathrm{ni}}=177.2 \mathrm{Wm}^{-2}\right)$ the $\mathrm{r}_{\mathrm{cl}}$ deviation is much larger, about 0.3 Clo. Large $r_{c l}$ deviations seem to be more typical in the case of heat excess, as in the course of occasions 55, 60, 65, 70 and 105. The largest $r_{c l}$ deviation is denoted for occasion $55\left(\mathrm{~T}_{\mathrm{a}}=23^{\circ} \mathrm{C}, \mathrm{R}_{\mathrm{ni}}=452.9\right.$ $\left.\mathrm{Wm}^{-2}\right)$, when the average wind speed is small $(0.5 \mathrm{~ms}$ $\left.{ }^{1}\right)$, but wind gust speed is unequivocally larger than the average wind speed $\left(2.5 \mathrm{~ms}^{-1}\right)$. In this case, $\mathrm{r}_{\mathrm{cl}}$ changed from -3.02 for average wind speed to -1.81 Clo for wind gust speed, the corresponding $\mathrm{T}_{\mathrm{o}}$ values changed from $70{ }^{\circ} \mathrm{C}$ to $54.7^{\circ} \mathrm{C}$, respectively. Note that on occasions 60 ,
65, 70 and 105 the average wind speed is not less than 1.7 $\mathrm{ms}^{-1}$, that is, it cannot be considered as small. Moderate or larger $r_{c l}$ deviations can also be observed in the case of thermal neutrality ( $\mathrm{r}_{\mathrm{cl}}$ close to zero), as on occasions 68 and 78 . Occasion 78 is interesting from that point of view that wind variation (average wind speed $0.3 \mathrm{~ms}^{-1}$, wind gust speed $1.4 \mathrm{~ms}^{-1}$ ) changed $\mathrm{r}_{\mathrm{cl}}$ from -0.2 Clo (a case of light heat excess, a cooling garment is needed) to $0.3 \mathrm{Clo}$ (case of light heat deficit, a heating garment is needed). The same effect of wind variation on $r_{c l}$ deviations can also be observed for occasion 76 .

\section{Sensitivity of $r_{c l}$ to interperson variations of $M$}

Table 1 reveals that $\mathrm{M}$ for a human walking at a speed of $1.1 \mathrm{~ms}^{-1}$ can vary a few tens of $\mathrm{Wm}^{-2}$ from human to human, so interperson $r_{c l}$ variations are also expected. $\mathrm{r}_{\mathrm{cl}}$ values for person $1\left(\mathrm{r}_{\mathrm{cl}}{ }^{1}\right)$ and $3\left(\mathrm{r}_{\mathrm{cl}}{ }^{3}\right)$ for all $112 \mathrm{oc}-$ casions are compared separately for average wind and wind gust in Figures 5 and 6, respectively.

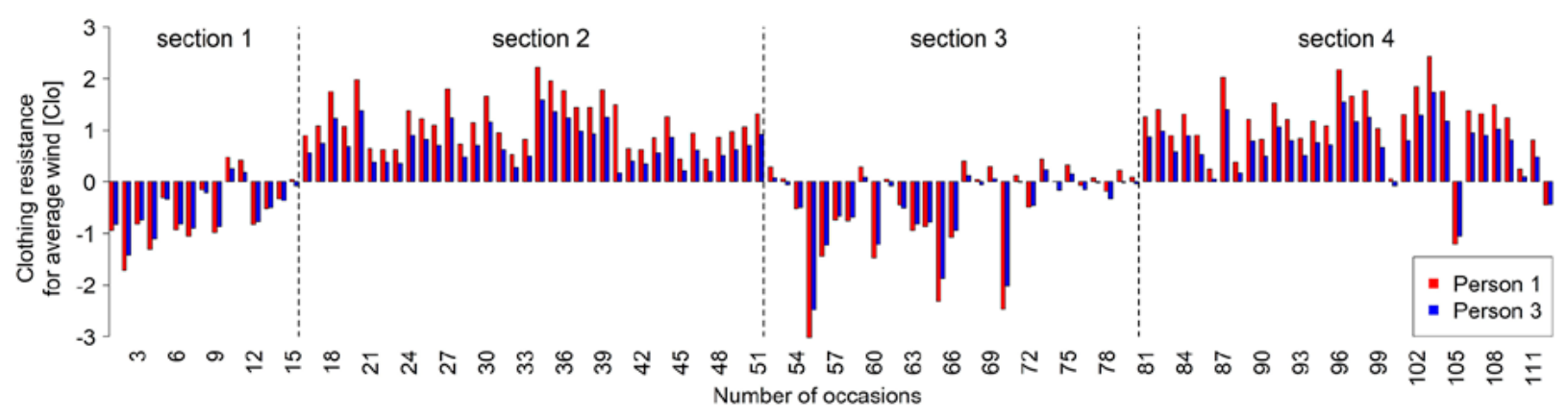

Figure 5. Evolution of clothing resistances of person 1 and 3 for average wind speed in course of running at the Martonvásár athletics track 


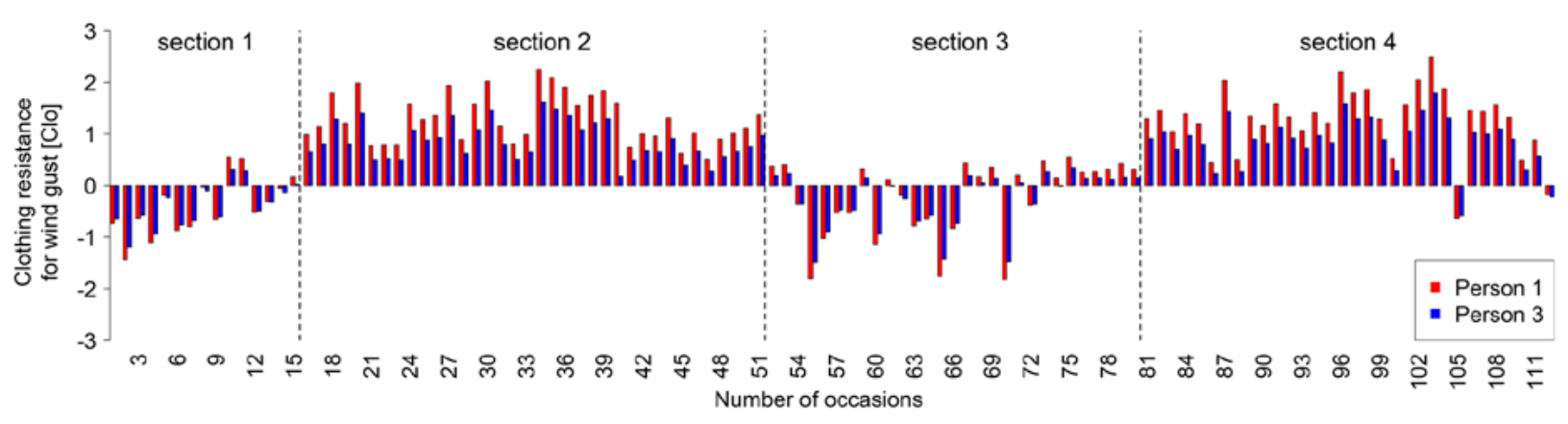

Figure 6. Evolution of clothing resistances of person 1 and 3 for wind gust speed in course of running at the Martonvásár athletics track

In both figures, systematic differences between $\mathrm{r}_{\mathrm{cl}}{ }^{1}$ and $\mathrm{r}_{\mathrm{cl}}{ }^{3}$ can be easily observed. In heat deficit cases $\left(r_{c l}>0\right), r_{c l}{ }^{1}>r_{c l}{ }^{3}$; in heat excess cases $\left(r_{c l}<0\right), r_{c l}{ }^{3}>$ $\mathrm{r}_{\mathrm{cl}}{ }^{1}$. In both cases, the relationship between $\mathrm{r}_{\mathrm{cl}}{ }^{1}$ and $\mathrm{r}_{\mathrm{cl}}{ }^{3}$ is determined with the fact that $\mathrm{M}^{3}>\mathrm{M}^{1}\left(\mathrm{M}^{1}, \mathrm{M}^{3}\right.$ are the metabolic activities of persons 1 and 3 , respectively). For instance, in a heat deficit case, when a heating garment is needed, less heating is needed for person 3 than for person 1 , since $M^{3}>M^{1}$. Vice versa, in a heat excess case, when a cooling garment is needed, less cooling is needed for person 3 than for person 1 , when $T_{o}>T_{S}$, and vice versa, larger cooling is needed for person 3 than for person 1 , when $T_{o}<T_{S}$. These latter cases can be observed during occasions $5,8,14$, 62, 76 and 78. $r_{\mathrm{cl}}$ differences of about 0.3 Clo appeared many times, for instance, on occasions $18,20,27,30$, $\mathrm{r}_{\mathrm{cl}}$ differences are slightly larger for average wind than for wind gust.

The $\mathrm{r}_{\mathrm{cl}}\left(\mathrm{T}_{\mathrm{o}}\right)$ point distribution is of special importance; this point distribution can be called a personenvironment-curve. Personal characteristics are represented via $M$ in $r_{c l}$, environmental characteristics are in both $\mathrm{r}_{\mathrm{cl}}$ and $\mathrm{T}_{\mathrm{o}}$, but $\mathrm{T}_{\mathrm{o}}$ is much less dependent on personal characteristics than $r_{c l}$. Personal characteristics in $T_{0}$ are represented via $D$ in the calculation of $r_{\mathrm{Ha}}$, but $\mathrm{D}$ does not change so strongly from person to person as, for instance, $U_{1.5}$ over the course of the time. In our analysis, $\mathrm{D}$ is taken as constant. The $\mathrm{r}_{\mathrm{cl}} \mathrm{T}_{\mathrm{o}}$ point distributions for persons 1,2 and 3 for all 112 occasions separately for average wind and wind gust are presented in Figs. 7 and 8, respectively. The largest interperson variations of $r_{c l}$ can be observed for average

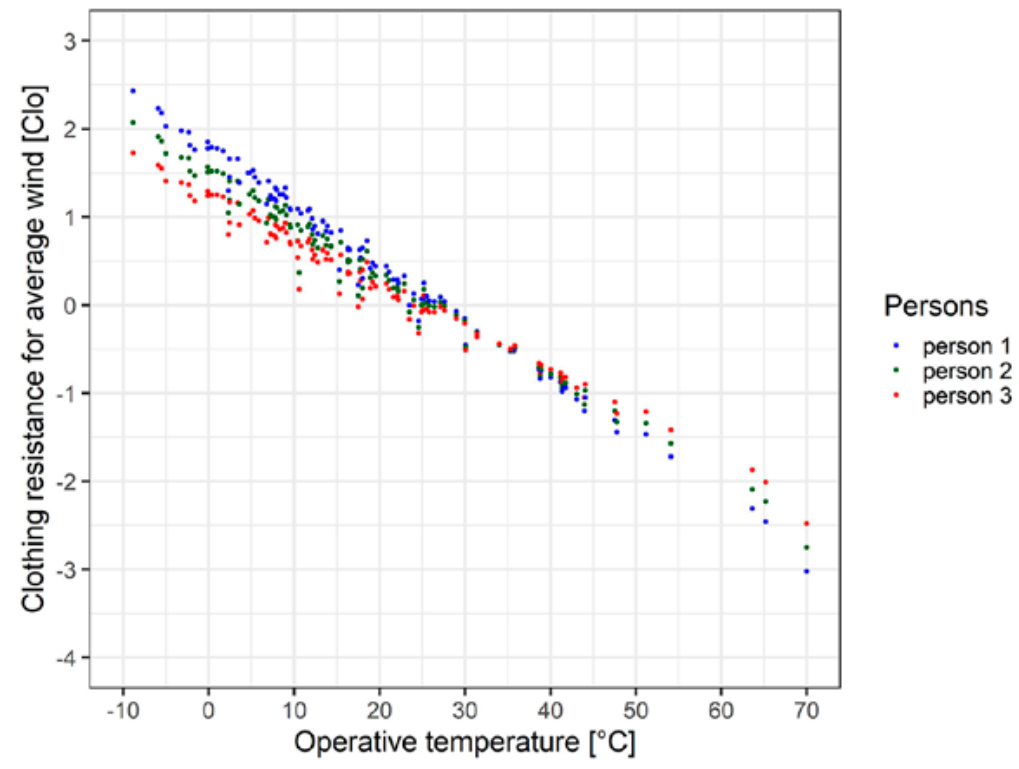

Figure 7. Clothing resistance-operative temperature dependence for average wind and for the persons considered. The number of points for one person is equal to the number of occasions

$34,35,36,38,39,50,60,65,70,87,91,96,97,98$ and 111. The largest interperson $\mathrm{r}_{\mathrm{cl}}$ differences amount to about 0.5-0.6 Clo. It should be mentioned that interperson
2 Figure is constructed by $\mathrm{R}$ functions from ggplot2 package (Wickham, 2016). 


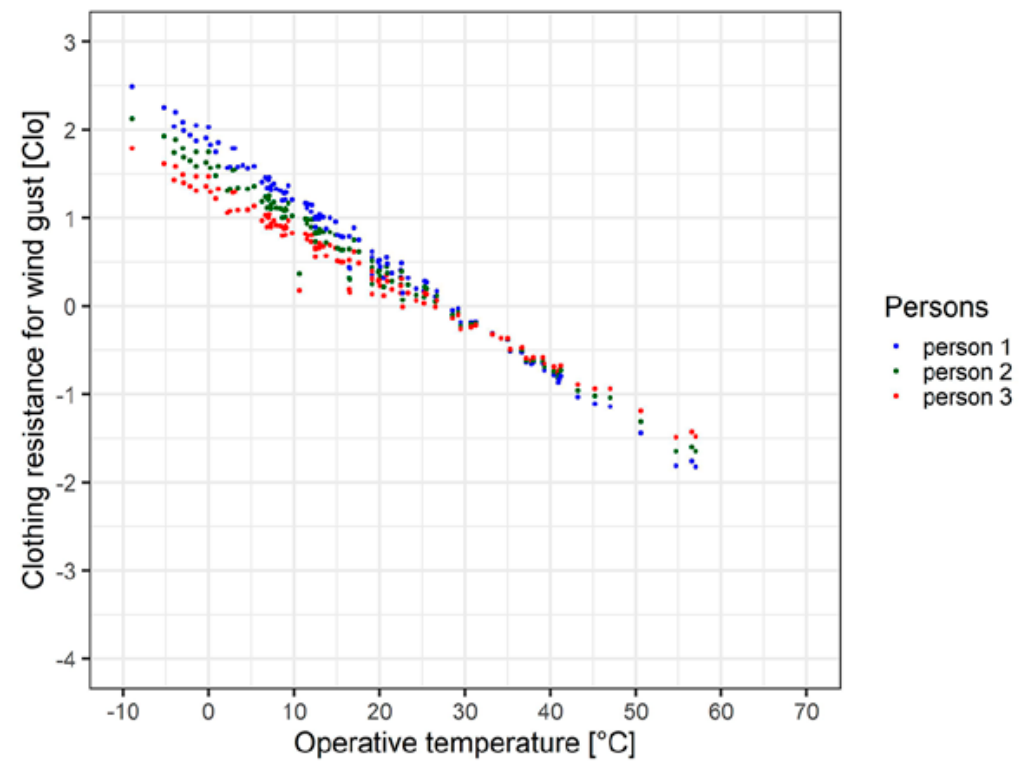

Figure 8. Clothing resistance-operative temperature dependence for wind gust and for the persons considered. The number of points for one person is equal to the number of occasions

wind case in extremely warm and cold situations. For $\mathrm{T}_{\mathrm{o}}=-8.9{ }^{\circ} \mathrm{C} \mathrm{r}_{\mathrm{cl}}$ varies from 2.43 Clo through 2.13 Clo to $1.73 \mathrm{Clo}$; similarly, for $\mathrm{T}_{\mathrm{o}}=70{ }^{\circ} \mathrm{C} \mathrm{r}_{\mathrm{cl}}$ variations are from -3.02 through -2.75 to $-2.48 \mathrm{Clo}$. As we see, the maximum range of interperson $r_{c l}$ variations can be above 0.5 Clo, when $T_{0}$ is either extreme cold or extreme warm. Of course, larger $\mathrm{T}_{0}$ extremes than those registered can happen in Hungary. Note that interperson $\mathrm{r}_{\mathrm{cl}}$ variations are much smaller, almost negligible, in the vicinity of thermal neutrality $\left(\mathrm{r}_{\mathrm{cl}}\right.$ values around zero), often called the comfort zone. For the persons considered and for average wind speeds, the comfort zone is in the $24-28{ }^{\circ} \mathrm{C}$ operative temperature interval. For wind gust speeds, this temperature interval is somewhat higher. The smallest interperson $r_{c l}$ variations are in those points for which $\mathrm{T}_{\mathrm{o}}$ is very close to $\mathrm{T}_{S}$ (see eq. 4). For average wind, $\mathrm{T}_{\mathrm{o}}=34^{\circ} \mathrm{C}$ on occasion 112 (May 23, 2018), in this case there is only 1 point instead of 3 points. For wind gust, $\mathrm{T}_{\mathrm{o}}=34.2^{\circ} \mathrm{C}$ on occasion 54 (May 19, 2017) and $\mathrm{T}_{\mathrm{o}}=33.2^{\circ} \mathrm{C}$ on occasion 13 (October 1, 2016), in these two cases closest to $T_{S}$ practically 1 point can be seen instead of 3 points. Figs. 7 and 8 differ not only in these nuances, but also in the $T_{0}$ ranges. For average wind, the $\mathrm{T}_{\mathrm{o}}$ range is roughly between -10 and $70{ }^{\circ} \mathrm{C}$, while for wind gust between -10 and 57 ${ }^{\circ} \mathrm{C}$. The effect of wind gust with respect to average wind on $\mathrm{T}_{\mathrm{o}}$ seems to be strong especially in the cases of large heat excess (occasions 55, 60, 65, 70). The largest $\mathrm{T}_{\mathrm{o}}$ shift towards lower values is obtained for occasion 55 (May 23, 2017), then $\mathrm{T}_{\mathrm{o}}$ decreased from 70 to $54.7^{\circ} \mathrm{C}$; the corresponding wind speed values are only 0.5 and $2.5 \mathrm{~ms}^{-}$ 1. The $\mathrm{T}_{\mathrm{o}}$ change is also great on occasion 70 (July 30, 2017), in this case $\mathrm{T}_{\mathrm{o}}$ dropped from 65.2 to $57.0^{\circ} \mathrm{C}$, the corresponding wind speed values are 1.7 and $4.7 \mathrm{~ms}^{-1}$. In a heat deficit case, occasions 30 and 90 can be mentioned, the simulated $\mathrm{T}_{\mathrm{o}}$ decreases are about $3{ }^{\circ} \mathrm{C}$. Occasion 100 can be mentioned as a case of thermal neutrality, then $\mathrm{T}_{\mathrm{O}}$ dropped from 24.9 (average wind of 1.7 $\mathrm{ms}^{-1}$ ) to $20^{\circ} \mathrm{C}$ (wind gust of $3.9 \mathrm{~ms}^{-1}$ ).

\section{Comparison of the two sensitivity test's results}

The effect of wind speed variation and the interperson variation of $\mathrm{M}$ on $\mathrm{r}_{\mathrm{cl}}$ (briefly WS and $\mathrm{M}$ effects) can be compared by parallel analysis of Figs. 4 and 5. It can be observed that the WS effect seems to be larger than the $M$ effect in heat excess cases (sections 1 and 3 in Figs. 2 or 4) and vice versa the $\mathrm{M}$ effect seems to be larger than the WS effect in heat deficit cases (sections 2 and 4 in Figs. 2 and 4). Of course, representation of wind speed variations and interperson variations of $M$ can vary; consequently the relationships obtained are valid strictly only for the conditions defined.

\section{Conclusions}

A new clothing resistance model for estimating outdoor thermal load is presented and its behavior is analyzed in different weather conditions. The basis of the model is formed by energy balance equations referring to human body-clothing and clothing-air environment interfaces. The human considered is a hu- 
man walking at a speed of $1.1 \mathrm{~ms}^{-1}$ who is not sweating. Weather data are taken from the internet site of the Hungarian Meteorological Service; the source of human data is a Hungarian human dataset constructed at the Department of Biological Anthropology, Eötvös Loránd University, Budapest (Zsákai et al., 2015). $r_{c l}$ is interpreted according to thermal equilibrium principles. It can be positive/negative when environmental heat deficit/excess exists, which can be brought to thermal equilibrium by using garments exerting heating/cooling effects. Such an interpretation of $r_{c l}$ is new. Simulated $r_{c l}$ values are not checked in a cold environment by independent registration of garments and by measuring their thermal conductivity. This is a task for the future. The scheme reproduces cold and thermally neutral situations well, similarly no weaknesses are registered in warm or extremely warm conditions. The sensitivity to interperson variations of metabolic activity showed by the scheme was not negligible. This sensitivity is the largest in extreme cold and/or warm conditions. Then the $\mathrm{r}_{\mathrm{cl}}$ differences registered can reach 0.5-0.7 Clo. In the comfort zone the sensitivity of $r_{c l}$ to interperson variations of $M$ is much less, and can be neglected. Under average wind speed conditions the thermal neutrality $\left(\mathrm{r}_{\mathrm{cl}} \approx 0\right)$ is located in the $24-28{ }^{\circ} \mathrm{C}$ operative temperature interval. $\mathrm{r}_{\mathrm{cl}}$ sensitivity to wind speed variations seems to be the largest in heat excess conditions. The largest $r_{c l}$ difference obtained in such a case is $1.2 \mathrm{Clo}$, the corresponding $\mathrm{T}_{0}$ values changed from 70 (average wind speed $0.5 \mathrm{~ms}^{-1}$ ) to 54.7 (wind gust speed $2.5 \mathrm{~ms}^{-1}$ ) ${ }^{\circ} \mathrm{C}$. This $\mathrm{r}_{\mathrm{cl}}$ difference is the largest among all $r_{c l}$ differences obtained in the scope of sensitivity tests. Regarding the effects of interperson variations of $\mathrm{M}$ and of changing wind velocity on the evolution of $\mathrm{r}_{\mathrm{cl}}$ under different thermal loads, a definite conclusion cannot be made. More tests have to be made taking into account larger variations in $\mathrm{M}$ and more extreme weather conditions. The scheme proposed is applied using weather data, but there is no obstacle for its application using climate data. Regardless of the data used one of the major strengths of the scheme is that it is able to treat interperson variations of the metabolic cost as simply as possible. We intend to use it in the future as software for characterizing personal heat thermal load of weather and/or climate.

\section{References}

Ács, F., Breuer, H., \& Skarbit, N. (2015). Climate of Hungary in the twentieth century according to Feddema. Theoretical and Applied Climatology, 119, 161-169.

Auliciems, A., \& de Freitas, C.R. (1976). Cold stress in Canada: A human climatic classification. International Journal of Biometeorology, 20(4), 287-294. doi:10.1007/bfo1553585

Auliciems, A., \& Kalma, J.D. (1979). A Climatic Classification of Human Thermal Stress in Australia. Journal of Applied Meteorology, 18(5), 616-626. doi:10.1175/1520-0450(1979)018<0616:accoht>2.0.c0;2

Błażejczyk, K., \& Krawczyk, B. (1994). Bioclimatic Research of the Human Heat Balance. Polish Academy of Sciences-Institute of Geography and Spatial Organization. No. 28, $66 \mathrm{pp}$.

Brownrigg, R. (2018). mapdata: Extra Map Databases. R package version 2.3.o. Original S code by R.A. Becker, A.R. Wilks; URL: https://CRAN.R-project. org $/$ package $=$ mapdata.

Brownrigg, R., Minka, T.P., \& Deckmyn, A. (2018). maps: Draw Geographical Maps. R package version 3.3.o. Original S code by R.A. Becker, A.R. Wilks; URL: https://CRAN.R-project.org/ package $=$ maps.

Brunt, D. (1932). Notes on radiation in the atmosphere. I. Quarterly Journal of the Royal Meteorological Society, 58(247), 389-420. doi:10.1002/qj.49705824704
Burton, A.C., \& Edholm, O.G. (1955). Man in a Cold Environment. London: Edward Arnold Ltd.

Campbell, G.S., \& Norman, J.M. (1998). An Introduction to Environmental Biophysics. New York: Springer. doi:10.1007/978-1-4612-1626-1

de Freitas, C.R. (1979). Human climates of Northern China. Atmospheric Environment (1967), 13(1), 71-77. doi:10.1016/0004-6981(79)90246-4

Dubois, D., \& Dubois,E.F.(1915). The Measurement of the Surface Area of Man. Archives of Internal Medicine, XV(5_2), doi:10.1001/archinte.1915.00070240077005

Frankenfield, D., Roth-Yousey, L., \& Compher, C. (2005). Comparison of Predictive Equations for Resting Metabolic Rate in Healthy Nonobese and Obese Adults: A Systematic Review. Journal of the American Dietetic Association, 105(5), 775-789. doi:10.1016/j.jada.2005.02.005

Herrington, L.P., Winslow, C.-.A., \& Gagge, A.P. (1937). The relative influence of radiation and convection upon vasomotor temperature regulation. American Journal of Physiology-Legacy Content, 120(1), 133-143. doi:10.1152/ajplegacy.1937.120.1.133

Katić, K., Li, R., \& Zeiler, W. (2016). Thermophysiological models and their applications: A review. Building and Environment, 106, 286-300. doi:10.1016/j. buildenv.2016.06.031

Konzelmann, T., van de Wal, R.S., Greuell, W., Bintanja, R., Henneken, E.A., \& Abe-Ouchi, A. (1994). 
Parameterization of global and longwave incoming radiation for the Greenland Ice Sheet. Global and Planetary Change, 9(1-2), 143-164. doi:10.1016/09218181(94)90013-2

Lees, J.M. (2018). GEOmap: Topographic and Geologic Mapping. R package version 2.4-4. URL https:// CRAN.R-project.org/package=GEOmap.

Lees, J.M. (2012). geomapdata:Datafor topographic and Geologic Mapping. R package version 1.0-4; URL: https://CRAN.R-project.org/package=geomapdata.

Nychka, D., Furrer, R., Paige, J., \& Sain, S. (2017). fields: Tools for spatial data. R package version 9.9; URL: https://cran.r-project.org/web/packages/fields/index.html. DOI: 10.5065/D6W957CT.

Matzarakis, A. (2007). Climate, thermal comfort and tourism. In B. Amelung, K. Blazeyczyk, \& A. Matzarakis (Eds.), Climate Change and Tourism: Assessment and Coping Strategies. Maastricht -Warsaw -Freiburg: Polish Academy of Sciences - Institute of Geography and Spatial Organization. pp 140-154; ISBN: 978-00-023716-4.

Mifflin, M.D., St, J.S.T., Hill, L.A., Scott, B.J., Daugherty, S.A., \& Koh, Y.O. (1990). A new predictive equation for resting energy expenditure in healthy individuals. The American Journal of Clinical Nutrition, 51(2), 241-247. doi:10.1093/ajcn/51.2.241

Mihailović, D.T., \& Ács, F. (1985). Calculation of daily amounts of global radiation in Novi Sad. Idójárás, 257-261; 89; in Hungarian.

Potchter, O., Cohen, P., Lin, T., \& Matzarakis, A. (2018). Outdoor human thermal perception in various climates: A comprehensive review of approach- es, methods and quantification. Science of The Total Environment, 631-632, 390-406. doi:10.1016/j.scitotenv.2018.02.276

R Core Team. (2019). R: A Language and Environment for Statistical Computing. Vienna, Austria: R Foundation for Statistical Computing. URL: http:// www.R-project.org/.

Robaa, S.M., \& Hasanean, H.M. (2007). Human climates of Egypt. International Journal of Climatology, 27(6), 781-792. doi:10.1002/joc.1434

Zsákai, A., Mascie-Taylor, N., \& Bodzsár, É.B. (2015). Relationship between some indicators of reproductive history, body fatness and the menopausal transition in Hungarian women. Journal of Physiological Anthropology, 34(1), 35-42. DOI: 10.1186/ s40101-015-0076-0.

Yan, Y.Y., \& Oliver, J.E. (1996). The Clo: A Utilitarian Unit to Measure Weather/Climate Comfort. International Journal of Climatology, 16(9), 1045-1056. doi:10.1002/(sici)1097-0088(199609)16:9<1045::aidjoc73>3.3.co;2-f

Yan, Y.Y. (2005). Human Thermal Climates in China. Physical Geography, 26(3), 163-176. doi:10.2747/0272-3646.26.3.163

Weyand, P.G., Smith, B.R., Puyau, M.R., \& Butte, N.F. (2010). The mass-specific energy cost of human walking is set by stature. Journal of Experimental Biology, 213(23), 3972-3979. doi:10.1242/jeb.048199

Wickham, H. (2016). ggplot2: Elegant Graphics for Data Analysis. Springer - Verlag. ISBN 978-3-31924277-4; URL: http://ggplot2.org. 